Molecules 2003, 8, 727

molecules

ISSN 1420-3049

http://www.mdpi.org

\title{
Editorial
}

\section{Policy Change Concerning Sample Submission}

Since its inception it has been the policy of Molecules that authors that could not (or did not want to) pay our page charges and were not eligible for a subsidy under the terms of our Open Access agreement with the Soros Foundation, could submit chemical samples to MDPI in lieu of payment. This has been clearly stated in our Instructions for Authors and all authors are reminded in the messages acknowledging receipt of their manuscripts.

It is with regret that we now announce that effective immediately and until further notice, we shall no longer be accepting sample submissions as payment of page charges. The reasons for this policy change are twofold. On the one hand, we have always operated on an honour system, whereby peerapproved papers were published when ready and afterwards we would arrange for either page charge payment or sample submission, but increasingly we have been victimized by unscrupulous authors, who after their papers have been published, do not send any samples or then refuse to pay the agreed amounts. This both threatens the viability of Molecules, its sister publications and the programs it supports and is patently unfair to those authors who do "follow the rules".

On the other hand, due to international events known to all, transborder shipments of chemical samples have come under increasing scrutiny by authorities and many submitters of samples have not followed our clear instructions for proper packaging, documentation and shipment of their samples, which not surprisingly, have in some cases been rejected and returned to their senders. The fact that unidentified white powders in an unlabelled plastic bag or even loose in an envelope might make the authorities suspicious should not surprise anyone. Furthermore, even if received, these samples cause great problems at MDPI where we cannot safely handle and store chemicals received in this manner.

We will continue to work with the members of our Editorial Board to find a satisfactory solution to this problem, but in the meantime, copies of this editorial will be sent to all authors with pending manuscripts and we shall assist them in any way we can to find alternate venues for their manuscripts should they now wish to withdraw them.

Dr. Derek McPhee

Managing Editor, Molecules

(C) 2003 by MDPI (http://www.mdpi.org). Reproduction is permitted for noncommercial purposes. 